\title{
Villous adenoma of papilla of Vater
}

\author{
SR CHOUdHURY, MS, DNB, AK MALIK, MD, Y CHAWLA, MD, DM, JD WIG, MS, FRCS
}

ABSTRACT: Biliary obstruction due to a benign villous adenoma of the ampulla of Vater treated by transduodenal local excision and sphincteroplasty is reported. Local surgical resection enabled a submucosal resection of the adenoma. Can J Gastroenterol 1990;4(6):235-236

Key Words: Ampulla of Vater, Benign tumour, Jaundice surgery

\section{Adénome villeux de la papille de Vater}

RESUME: On rapporte un cas d'obstruction biliaire dû à un adénome villeux de la papille de Vater et traitée par exérèse locale transduodénale et sphinctéroplastie. Une résection chirurgicale locale a permis la résection sousmuqueuse de l'adénome.

B
RENIGN TUMOURSOF THE AMPULLA of Vater are uncommon lesions; about 100 such cases have been reported in the English medical literature $(1,2)$. With endoscopic retrograde cholangiopancreatography, a preoperative diagnosis and appropriate therapeutic planning is possible (3).

\section{CASE PRESENTATION}

A 55-year-old female diabetic on oral hypoglycemic drugs presented with episodic, colicky pain in the right hypochondrium of three months duration. She had an episode of cholangitis - fever with chills and rigors, and jaundice six weeks prior to presentation. Physical examination revealed mild icterus, a smooth nontender liver $4 \mathrm{~cm}$ below the costal margin, and a palpable, tender gallbladder. Serum bilirubin was initially elevated at $3 \mathrm{mg} / \mathrm{dL}(51 \mu \mathrm{mol} / \mathrm{L})$. Serum alkaline phosphatase was $114 \mathrm{iu} / \mathrm{L}$, and an ultrasound scan showed a distended gallbladder and a common bile duct dilated to its lower end. The
Departments of Surgery, Hepatology, Gastroenterology and Pathology, PGIMER, Chandigarh, India

Correspondence and reprints: Dr JD Wig, PGIMER, Chandigarh 160012, India

Received for publication May 1, 1990. Accepted July 13, 1990 pancreatic head was normal. Endoscopy revealed a friable, polypoidal growth at the papilla and endoscopic punch biopsy revealed villous adenoma with moderate dysplasia.

Surgical exploration revealed a distended gallbladder and a dilated common bile duct. A firm nodular mass was palpable through the duodenal wall in its second part.

Duodenotomy revealed a firm, friable, bosselated polypoidal mass (1.5x $\left.2.0 \times 1.0 \mathrm{~cm}^{3}\right)$ at the papilla. A submucosal excision of the mass and reconstruction of the common bile duct and pancreatic duct was performed. Frozen section was reported as villous adenoma without any evidence of malignancy. The patient had an uneventful postoperative period. Histopathology of the resected mass showed a villoadenomatous polyp. Multiple sections did not reveal any foci of overt malignancy.

\section{DISCUSSION}

Benign periampullary tumours are rare (less than $10 \%$ of all periampullary tumours) (1), and of all reported benign tumours, villous adenoma is the most common (4). More than $75 \%$ of the reported patients were symptomatic (1) 


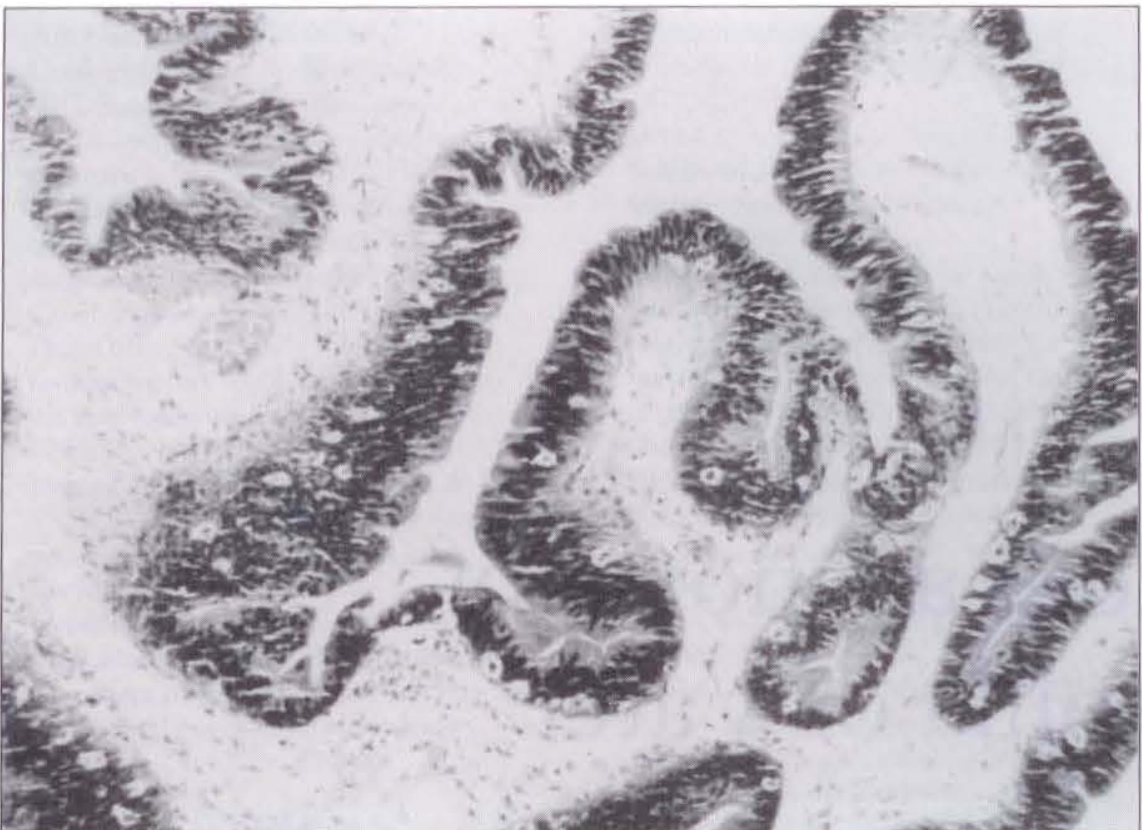

Figure 1) Microphotograph showing villous adenoma with mild cellular atypia (Hematoxylin and $\operatorname{eosin} \times 196$ )

with nonspecific symptoms of abdominal discomfort $(1,4,5)$, pain and weight loss $(90 \%)$, jaundice $(75 \%)$ $(1,6)$, pancreatitis $(7)$, upper gastrointestinal bleeding or duodenal obstruction $(5,8)$. Hepatomegaly and a palpable gallbladder may be present (9). Laboratory investigation may reveal raised serum bilirubin and alkaline phosphatase, anemia and occult blood in the stool. Radiological investigation may reveal a dilated common bile duct $(70 \%)$ or coexisting gallstones (13 to $20 \%$ of cases), and a barium study may produce a 'soap bubble' appearance (1). Upper gastrointestinal endoscopic biopsy is helpful in the diagnosis $(2,3)$.

On gross examination villous adenomas are fleshy, pink, nodular, pedunculated or sessile growths varying in size from 0.2 to $7 \mathrm{~cm}$ (4). Histological diagnosis is based on papillary and villous processes lined by tall columnar epithelium. Foci of malignancy have been noted in over $25 \%$ of patients who underwent surgical resection of the ampulla for benign adenoma $(1,10)$. Multiple sections did not reveal any foci of malignancy in the present patient. Patients with polyposis coli and Gard. ner's syndrome may have associated duodenal adenoma $(11,12)$. These lesions should be resected, the method of resection varying from endoscopic to surgical $(2,3)$. Once the frozen section examination has excluded malignancy, local submucosal excision with double sphincteroplasty of both the common bile duct and the pancreatic duct is the recommended procedure. If invasive carcinoma is suspected, pancreaticoduodenectomy is preferred $(1,2)$.

A recurrence rate of $28 \%$ has been reported following segmental resection, local excision or endoscopic excision (13). Sobal et al (1) have reported that more than $85 \%$ of patients treated by local surgical excision were without evidence of recurrence for varying periods of follow-up. Endoscopic fulguration of recurrent ampullary adenomas after local surgical excision is safe and effective in combination with snare polypectomy (2).

Only one of the five cases reported by Shemesh et al (2) developed adenocarcinoma 40 months after surgery, while 22 of the patients in the series of Galandiuk et al (13) who did not return for follow-up at six to 12 month intervals developed recurrent tumours with malignant change and died of cancer. It is thus advocated that fol. lowing local excision, the patients should be followed-up at six month intervals with endoscopy and biopsy $(12,13)$.

\section{REFERENCES}

1. Sobal S, Cooperman AM. Villous adenoma of the ampulla of Vater: An unusual case of biliary colic and obstructive jaundice. Gastroenterology 1978;75:107-9.

2. Shemesh E, Nass S, Czerniak A. Endoscopic sphincterotomy and endoscopic fulguration in the management of adenoma of the papilla of Vater. Surg Gynecol Obstet 1989;169:445-8.

3. Ponchon T, Berger F, Chavaillon A, et al. Contribution of endoscopy to diagnosis and treatment of tumours of the ampulla of Vater. Cancer 1989;64:161-7.

4. Oh C, Jemerin EE. Benign adenomatous polyp of the papilla of
Vater. Surgery 1965;57:495-503.

5. Schulten M, Oyasu R, Beal J. Villous adenoma of the duodenum. A case report and review of the literature. Am J Surg 1976;132:90-6.

6. Catell RB, Braasch JW, Kahn F. Polypoid epithelial tumours of the bile duct. N Engl J Med 1972;266:57-61.

7. Ohmori K, Kiroshita H, Shiaraha Y, et al. Pancreatic obstruction by a benign polypoid adenoma of the ampulla of Vater. Am J Surg 1976;132:662-3.

8. Neuman DH, Doerhoff CR, Bunt T]. Villous adenoma of the duodenum. Am Surg 1984;50:26-8.

9. Malik AK, Baruah MK, Pravin N, Katariya RN. Villous adenoma of the ampulla of Vater. Postgrad Med J 1985;61:1077-8.

10. Gouma DJ, Oberton H, Vismans J, et al. Progression of a benign epithelial ampullary tumour to adenocarcinoma. Surgery 1987;101:501-4.

11. Yao T, lida M, Ohsato K, et al. Duodenal lesions in familial polyposis of the colon. Gastroenterology 1977;73:1086-92.

12. Shemesh E, Bat L. A prospective evaluation of the upper gastrointestinal tract and periampullary region of patients with Gardner syndrome. Am Gastroenterol 1985;80:825-7.

13. Galandiuk S, Hermann RE, Jagelman DG, et al. Villous tumours of the duodenum. Ann Surg 1988;207:234-9. 


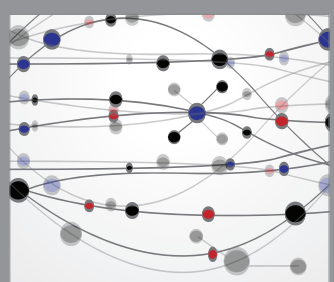

The Scientific World Journal
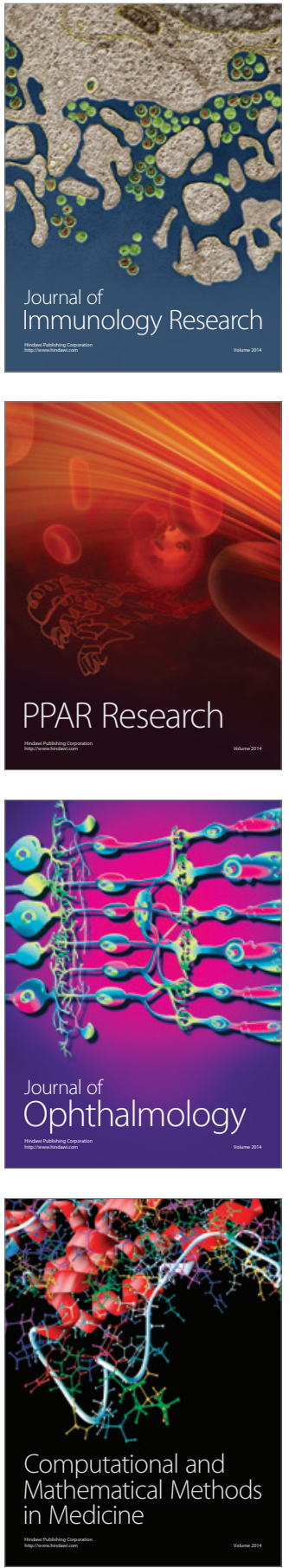

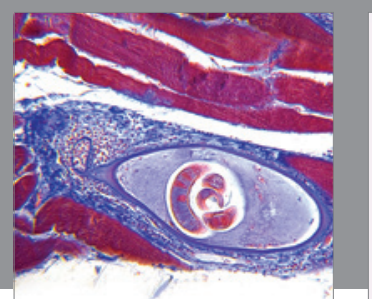

Gastroenterology Research and Practice

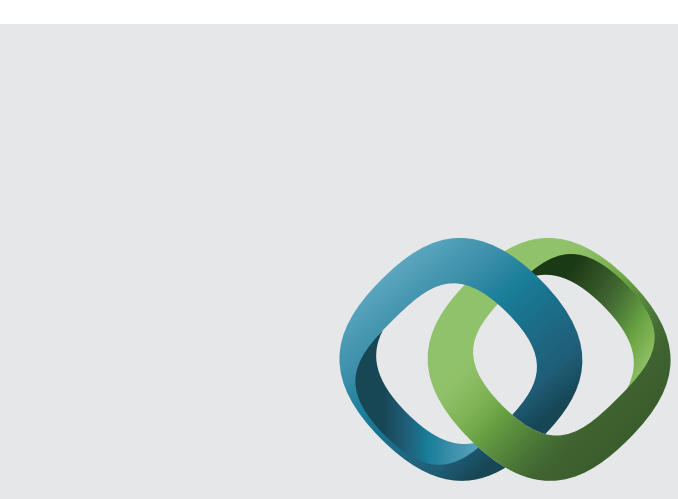

\section{Hindawi}

Submit your manuscripts at

http://www.hindawi.com
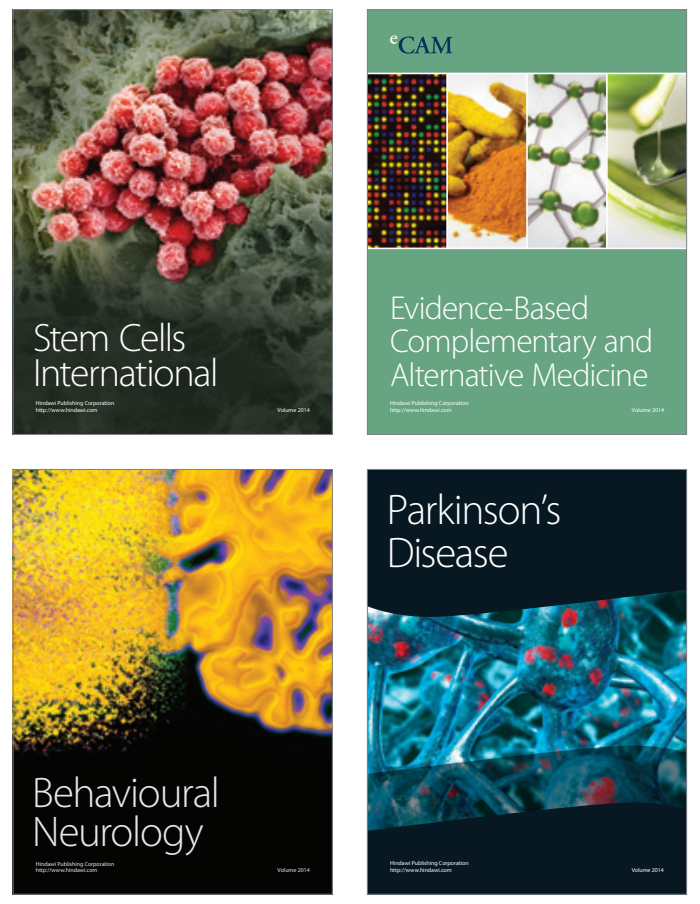


Disease Markers
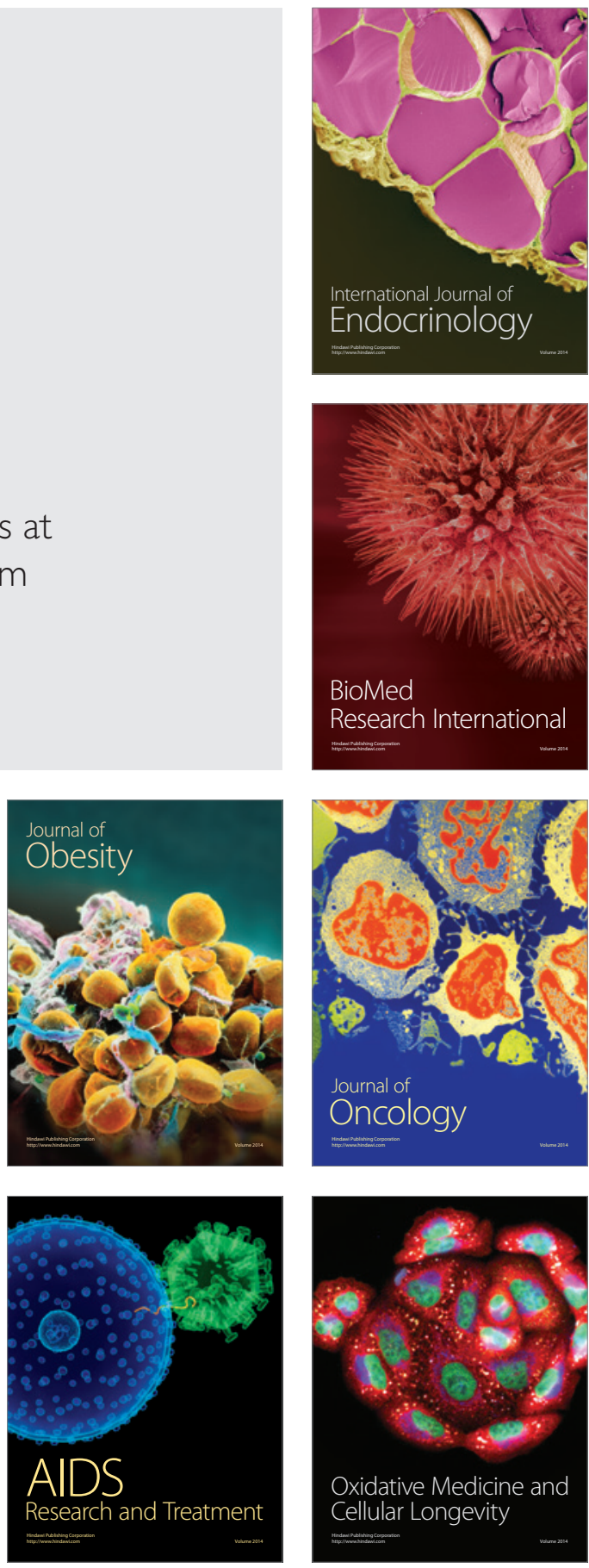